beautifully illustrated article on medical ophthalmology. by Dr. James Taylor, and one on the medical applications of Electricity, by Dr. Bertram Abrahams.

Dr. Allchin's third volume is, in our opinion, highly to be recommended. We know of no book in the language upon this subject which will be more worth the student's, and indeed the practitioner's, while to read and to possess.

F. W. T.

\section{PRACTICAL MATHEMATICS.}

Pructical Mathematics for Beginners. By Frank Castle, M.I.M.E. Pp. ix + 3i3. (London: Macmillan and Co., Ltd., I90I.) Price $2 s .6 d$.

THIS little book deserves the title of Practical 1 Mathematics better than any work that we have seen. The subjects dealt with are arithmetic, plane geometry, algebra, mensuration and analytic geometry. The chapters on arithmetic deal with those operations in which this subject is most nearly related to algebrasuch as the theory of fractions, ratio and the extraction of the square root. The part on geometry is strictly limited to constructions with rule, compass, \&c., and explains the use of simple and diagonal scales; it is in $\mathbf{n}$ j sense a course of deductive geometry such as we have in the books of Euclid. The part of the book dealing with algebra is more extensive, but still very elementary ; it does not, for example, include a discussion of quadratic equations, although it shows how a quadratic expression in $x$ can, in very simple cases, be resolved into factors. While noticing this part of the book we may point out some corrections which should be made in the next edition. Thus, in p. 76 , where it is proposed to resolve $x^{2}-9 x+20$ into factors, we find the statement, "Hence $x=4$, or $x-4=0$ is a factor." The beginner should be put on his guard against such a loose mode of expression. In the next example on the same page we find, "Next put $x=+5$, and it is found to be a factor." The factor referred to is $x-5$. In p. 77 we have the incorrect expression, "When required to add, subtract or compare fractional expressions, it is necessary that they shall all have a common denominator." In p. $88, g$ is described as $32^{\circ} 2$ "feet per second" instead of $32^{*} 2$ "feet per second per second," which the majority of mathematicians have at last been forced to acknowledge as the only correct mode of speaking.

These, however, are minor blemishes which are very casily removed.

It is a cardinal aim with the author to make all his examples illustrative of questions relating to various branches of physics, and for a certain class of students (those who have already come into contact with such practical matters) this is a very good plan, because it enlists the interest of the learner in convincing him that he is applying his mathematics to something real. It is doubtful if the plan has as much value for the ordinary schoolboy who is, under our precious system of education, a complete stranger to everything in the domain of physics. Hence such questions as that in example 5 , p. 88 , relating to the arrangement of a number of Grove's cells, will not convey much meaning to any but students of physics. There are useful little chapters on logarithms, NO. I675, vOL. 65$]$ showing their use and illustrating several things in which beginners are very apt to make mistakes. After chis we come to an explanation of the slide rule and its applications ; and the remainder of the book is that which most entitles it to the name of Practical Mathematics, this portion being of value to the student who wishes to be able to apply his pure mathematics to the representation of physical results. Here there is a great deal of graphic work done by means of squared paper, and a considerable portion of the analytic geometry of right lines, circles and higher curves is expounded, the accompanying illustracions being all drawn from physics. The fundamental notions of the differential calculus are very well and simply explained by this same system of plotting on squared paper; and the ease with which the processes can be followed and understood even by beginners who have nothing but a knowledge of arithmetic and elementary algebra to go upon shows that, in our ordinary course of mathematical teaching, the differential calculus is very unnecessarily postponed-that, in other words, our mathematical course for beginners should be made eclectic in character, a portion of any subject being introduced when the mind of the student is in a state to understand it. Our present system is essentially different; we feel constrained to finish each subject before beginning another, although the finish of one subject may be much more difficult than the preliminary portion of that which is postponed ; and we thus lose sight of the fact that our present divisions of mathematics are only artificial, and that mathematics is, in reality, one connected whole.

In the part of the work dealing with mensuration two planimeters are described-the Hatchet and Amsler's.

The work gives an excellent epitome of the various branches of mathematics dealt with, and it will serve as a store of very good exercises in elementary methods for all students who desire to make a practical use of their mathematical knowledge in picturing the relations between various physical quantities.

\section{OUR BOOK SHELF.}

Memorial Lectures delivered before the Chemical Society, I893-I900. Pp. 560. With fourteen portraits. (London : Gurney and Jackson, I90I.) Price 7s, 6d.

THE Chemical Society has done an important service to chemists and to students of chemistry by collecting these memorial lectures into one volume, and issuing it under conditions which render it accessible to readers of whom some may not be Fellows of the Society and consequently have not enjoyed the advantage of hearing the lectures when delivered or of reading them in the pages of the Transactions.

The lives of the men whose work and achievements are commemorated in this volume link us with the now long-distant past, and remind us of the immense strides which have been made in consequence of their discoveries and the discoveries of their contemporaries since the days when Berzelius and, later, Liebig were the dominant authorities. They remind us of the great and almost sudden advance which was accomplished between $185^{\circ}$ and 1865 , when the modern system of atomic weights, definite ideas of valency and constitutional formulæ were finally established. The student who aspires to understand by what methods and with what laborious effort the greatest degree of scientific accuracy is alone attainable must read about the work of Stas on atomic 